\title{
Original Research \\ Study of Ergonomic Conditions of University Libraries and its Impact on Librarians' Performance by Mediating Job Satisfaction in Order to Provide Model
}

\author{
Zivar Sabaghinejad ${ }^{1 *}$, Abdolkazem Neisi², Somaye Parvin ${ }^{3}$ \\ 1. Faculty Member, Ahvaz Jundishapur University of Medical Sciences, Ahvaz, Iran \\ 2. Faculty Member, Shahid Chamran University of Sciences, Ahvaz, Iran \\ 3. Ahvaz Jundishapur University of Medical Sciences, Ahvaz, Iran
}

\begin{tabular}{lr}
\hline \multicolumn{2}{c}{ Article Info } \\
\hline Original Article \\
\\
Received: & $2018 / 09 / 29$ \\
Accepted: & $2019 / 12 / 03$ \\
Published Online: & $2019 / 01 / 19$
\end{tabular}

DOI: $10.30699 /$ jergon.6.3.8

Use your device to scan and read the article online

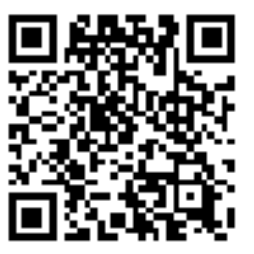

Corresponding Information

\section{Zivar Sabaghinejad}

Faculty Member, Ahvaz Jundishapur University of Medical Sciences, Ahvaz, Iran
Abstract
Background \& Objectives: Each organization needs to provide an environ- ment that is smooth, tensile, comfortable and affordable with appropriate physical and emotional conditions for each employee, a safe and relaxed working environ- ment, so that they can work best with a sense of job satisfaction. The present study examines the ergonomic conditions of libraries in public universities in Ahwaz and its impact on job satisfaction and librarians.

Methods: This research is descriptive and has been surveyed. The population of the study consisted of 84 librarians of Shahid Chamran Universities and Ahvaz Jundishapur University of Medical Sciences who participated in the study census. To evaluate ergonomic conditions, a questionnaire was extracted from ergotools software, job satisfaction survey from Arenson et al. Scale and job evaluation questionnaire by Faraj Pahloo, Nooshin Fard and Hasanzadeh. Relationships between research variables were investigated using structural equation modeling.

Results: The results showed that there is a direct, positive and significant relationship between ergonomic conditions and job satisfaction, job satisfaction and job performance, and ergonomic conditions and job performance. There is also a positive and significant indirect relationship between ergonomic conditions and job performance due to job satisfaction.

Conclusion: All relationships between the variables examined were confirmed. Therefore, ergonomic conditions are effective both directly and through the job satisfaction of librarians' job performance. Considering the positive and direct relationship, it can be said that the librarians of the public universities' libraries of Ahwaz are pleased with better ergonomic conditions and show better job performance.

Keywords: total ergonomics, job satisfication, job performance, libraians, physical conditions of the workplace.

Copyright (C) 2018, Journal of Ergonomics. This is an open-access article distributed under the terms of the Creative Commons Attribution-noncommercial 4.0 International License which permits copy and redistribute the material just in noncommercial usages, provided the original work is properly cited

How to Cite This Article:

Sabaghinejad Z, Neisi A, Parvin S. Study of Ergonomic Conditions of University Libraries and its Impact on Librarians' Performance by Mediating Job Satisfaction in Order to Provide Model. J Ergon. 2018; 6 (3): 75-85 


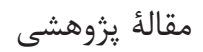

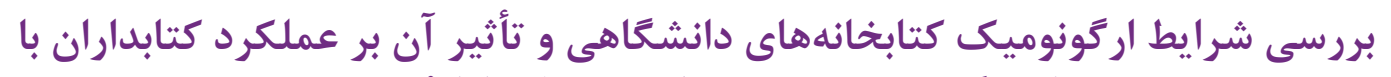

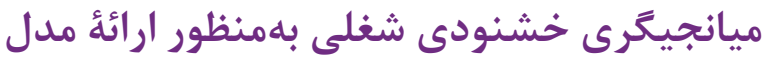 \\ زيور صباغىنزاد'"، عبدالكاظم نيسى'، سميه يروين
}

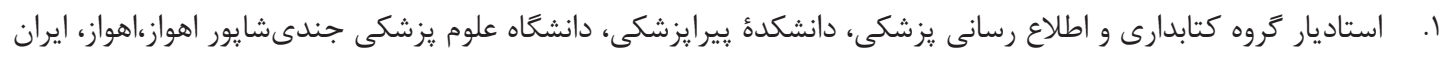

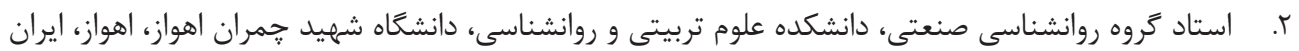

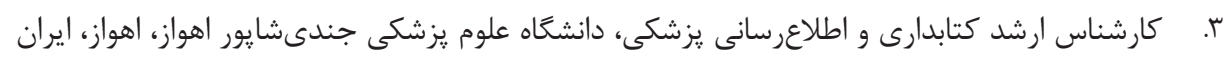

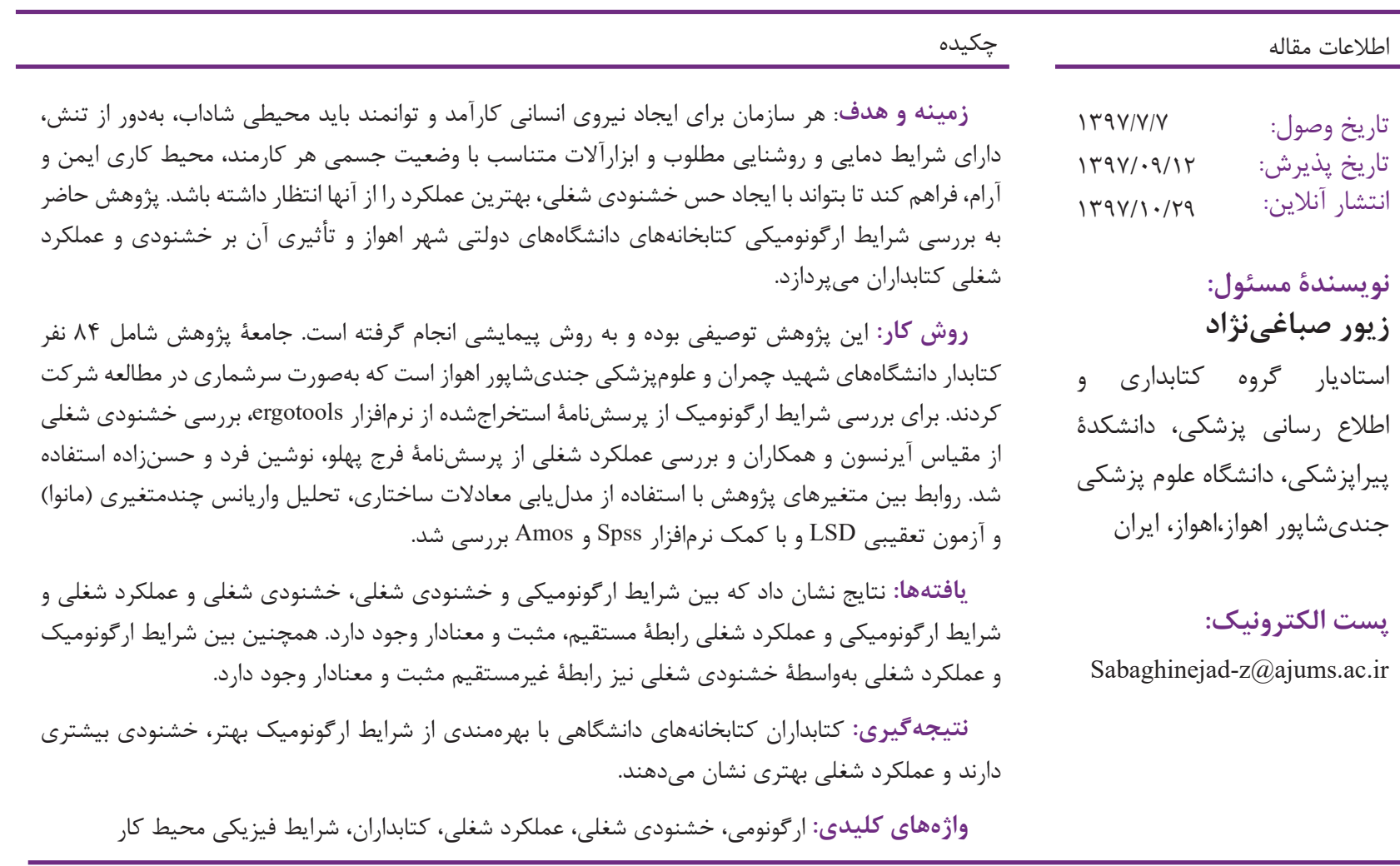

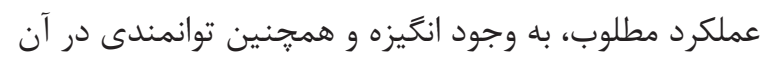

مقدمه

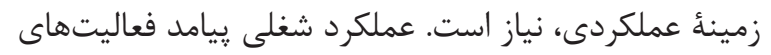

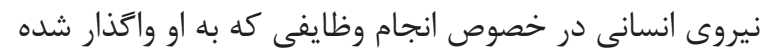

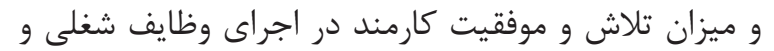

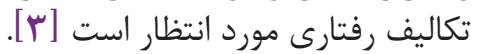

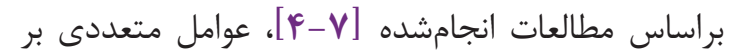

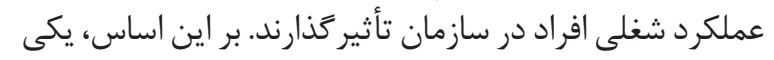

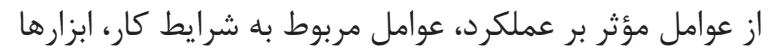

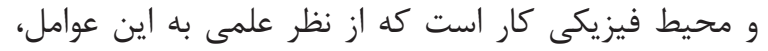

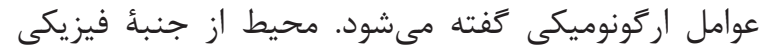

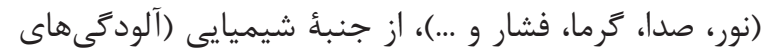

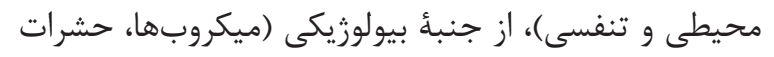

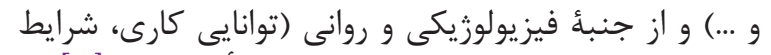

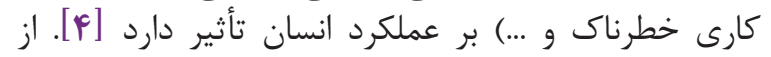

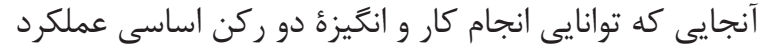

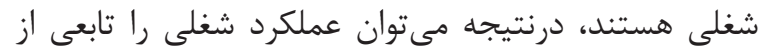

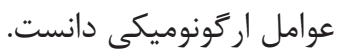

هر سازمان براى دستيابى به اهداف خود نياز دارد كه

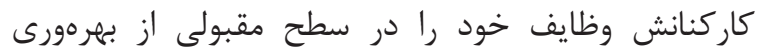

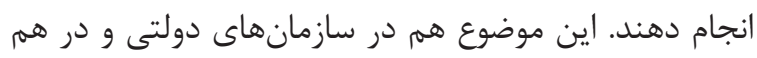

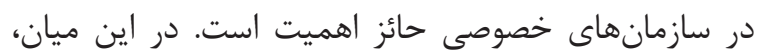

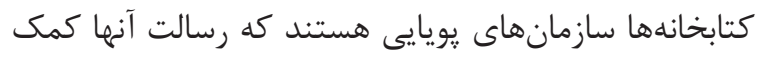

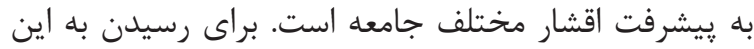

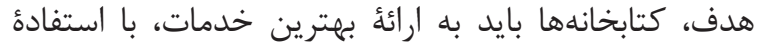

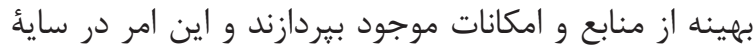
عملكرد شغلى مطلوب كتابداران ميسر خواهد شداند

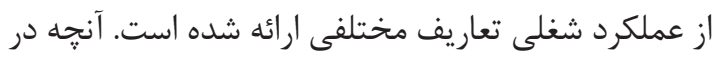

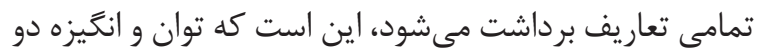

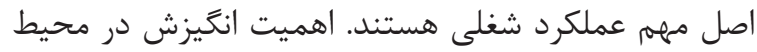

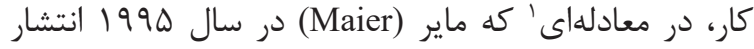
داد، مشخص شده است. ماير بيان مى كند كه برائ (لراى داشتن

$$
\text { ا.عملكرد شغلى= توانايى * انخيزش }
$$


• عوامل انسانى به عوامل شغلى، سازمانى و محيطى

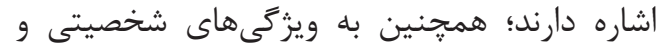

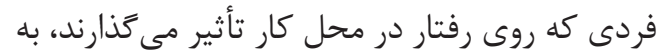
شيوهاى كه مى توانند روى سلامت رو ورى امنيت تأثير كذار

باشند [1.].

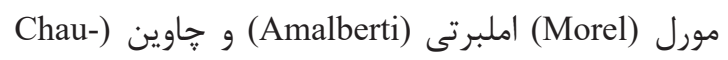

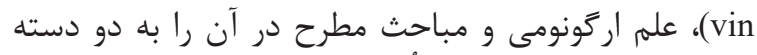

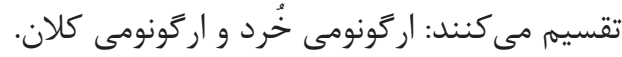

ميكروارگونومى يا ارگونومى خرد، بر سه حيطه تكيه

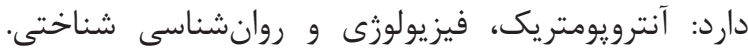

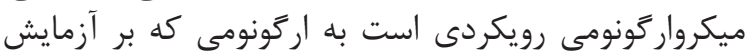

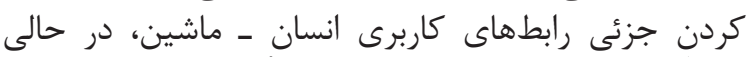

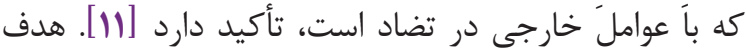

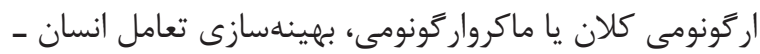

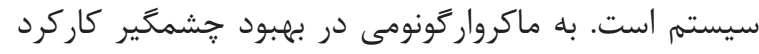

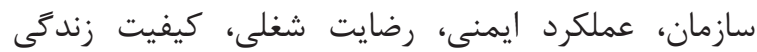

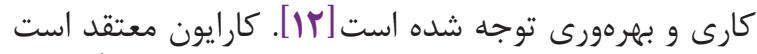
اركونومى كلان از اصول مديريت كيفيت توجيت جامع منشأ كرفته

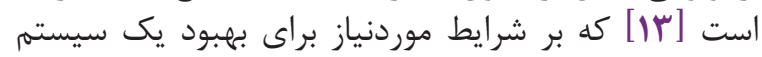

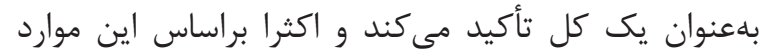
عمل مى كنند: تعداد، آموزش و رضاكيد رضيت كين واركنان، كيفيت

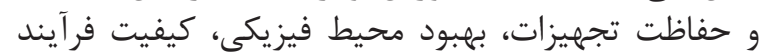
كارى، محصول اقتصادى.

مطالعة حاضر از نوع بررسى مقطعى بوده كه شرايط

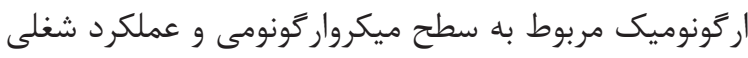
مربوط به سطح ماكروار گونومى است.

اجزاى مربوط به شرايط ارگونوميك شامل موارد ذيل

جانمايى ايستعاه كارى (فضاى كار و وسايل روى ميز

حمايت كننده صفحه كليد/ ورودى ها (درباره وضعيت

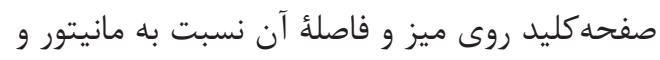

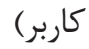

وضعيت نشستن (در مورد يك صندلى استاندارد از

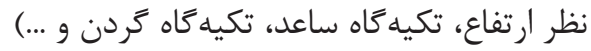
تجهيزات كامييوترى (در مورد دكمههاى صفحه كليد، جرخش و خمش مانيتور و ...) روشنايى (روشنايى محل كار، درخشندگى جراغ تهاى بالاى سر، نور مانيتور) محيط كار (از نظر دما، آلودگى هوا و غبار، سروصدا (... g

توجهات ويزه (ايستخاههاى كارى ايستاده و و

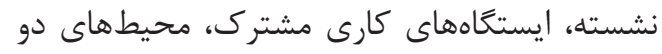

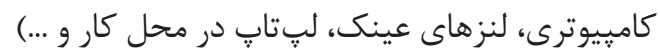

يكى ديگر از مواردى كه مىتواند بر عملكرد كاركنان

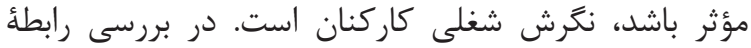

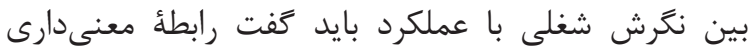

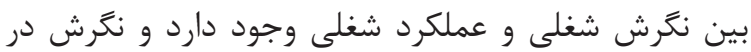

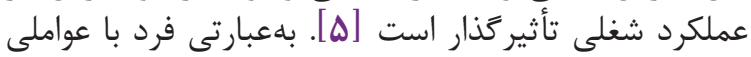

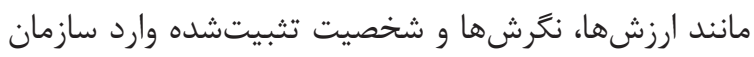

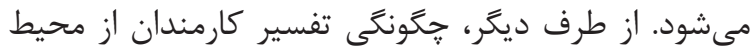

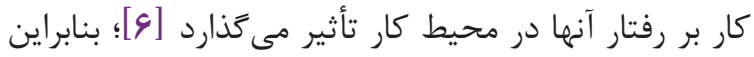

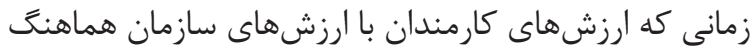

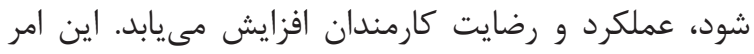

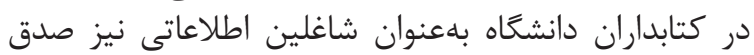

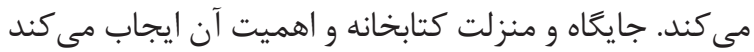

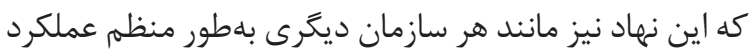

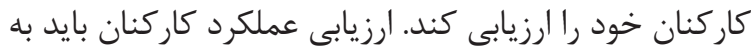

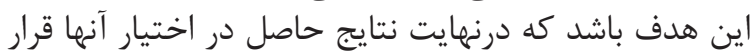

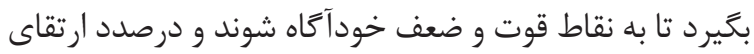

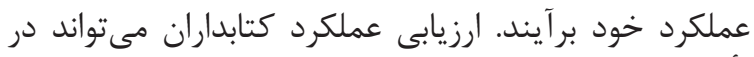

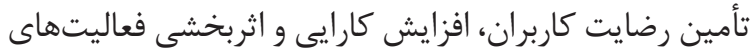

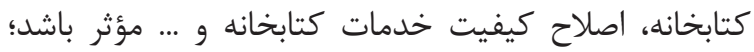

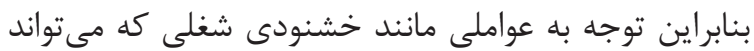
بر عملكرد مطلوب تأثير گذار باشد، حائز اهميت است است

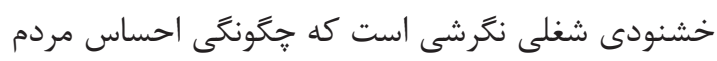

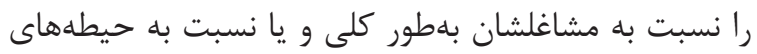

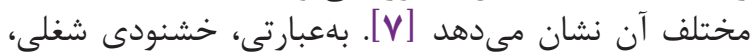

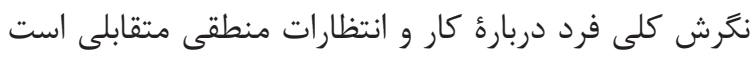

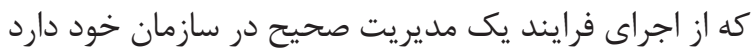

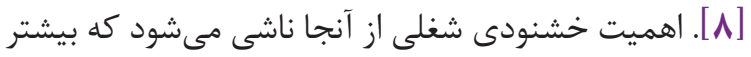

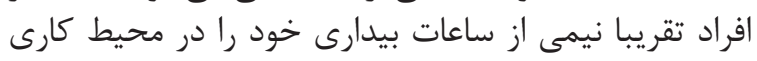

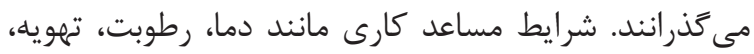

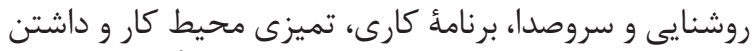

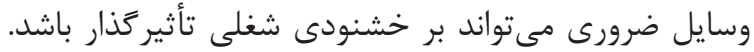

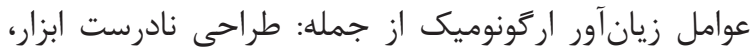

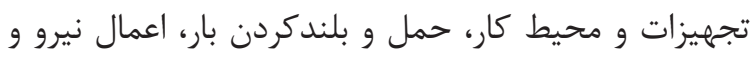

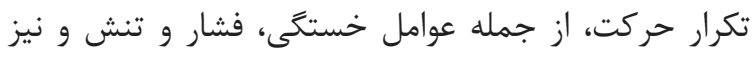

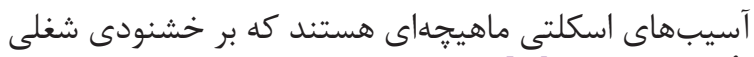
تأثير مى حذارند [V]

اركونومى، علمى است كه به انسان و برهم كنش او با

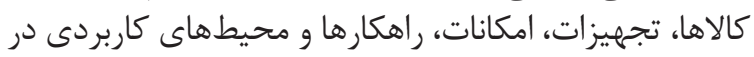

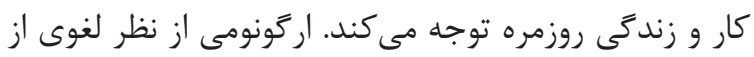

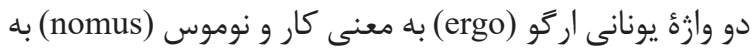

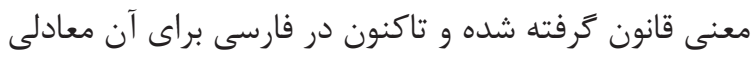
در نظر گرفته نشده است.

• از نظر انجمن بينالمللى ارگونومى، ارگونومى يا

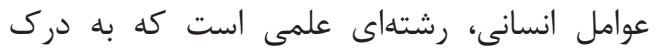
تعاملات بين انسان و ساير عناصر يك سيستم انتم مربوط مىشود و حرفهاى است كه تئورىها، اصول، دادهها و ونساص روشهايى را براى بهينهسازى سلامت انسان و روى روى

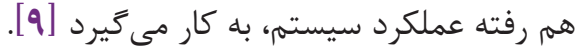



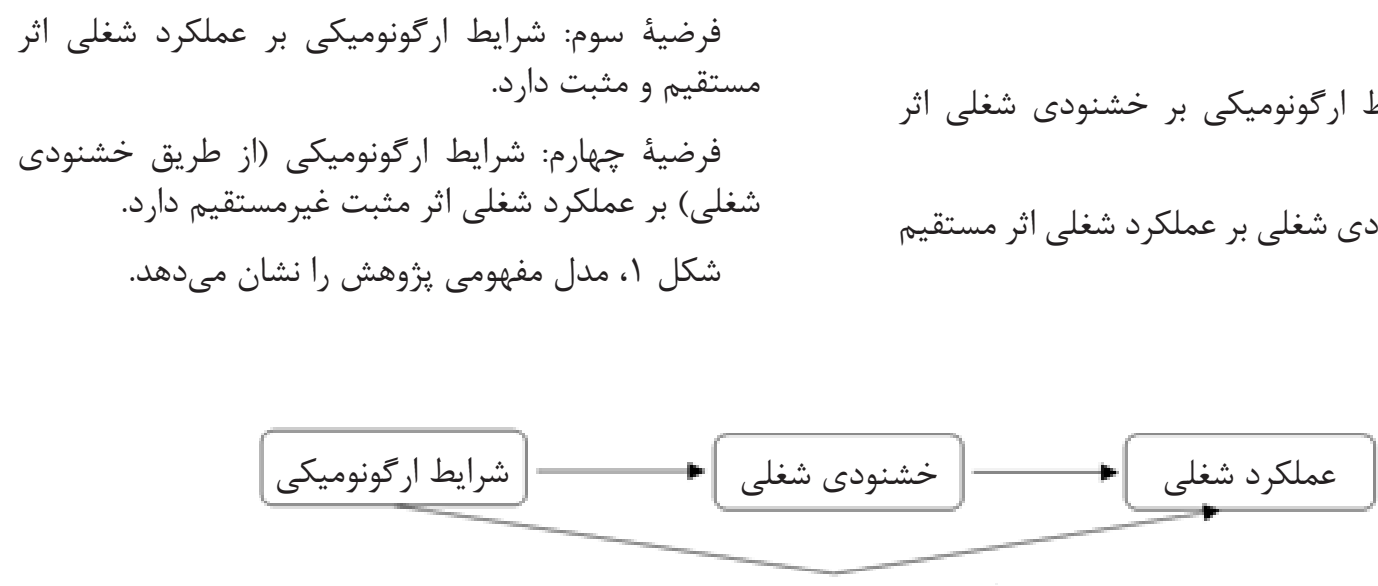

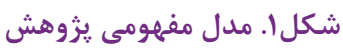

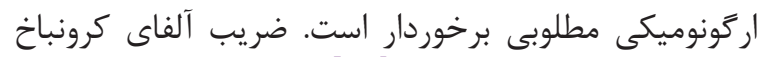

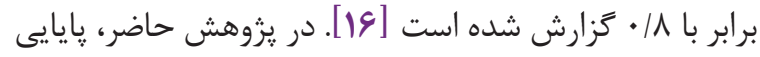

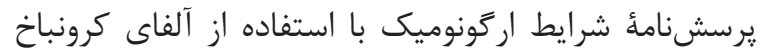

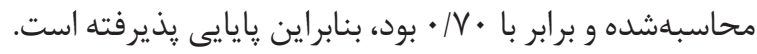

\section{بر رسى عملكرد شغلى}

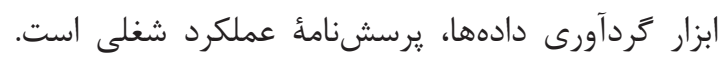

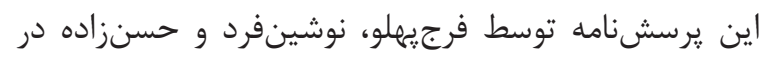

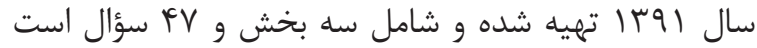

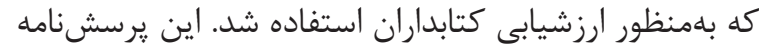

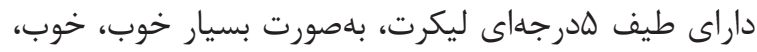

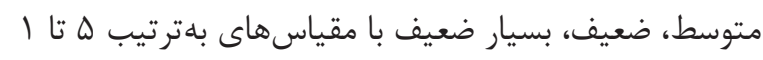

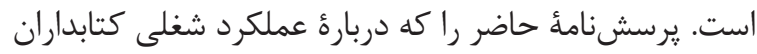

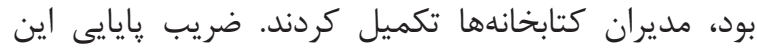

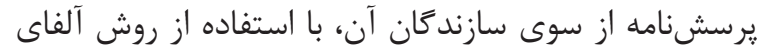

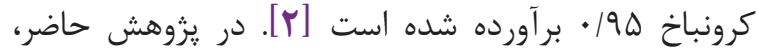

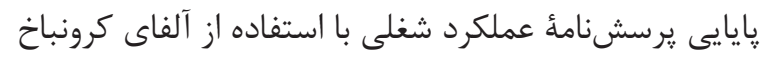

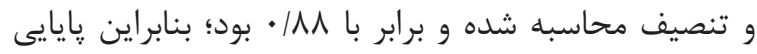

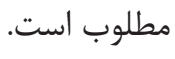

\section{جمع آورى دادهها}

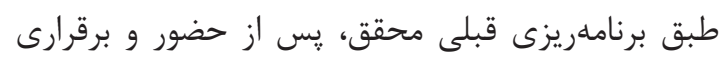

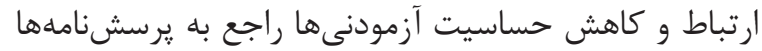

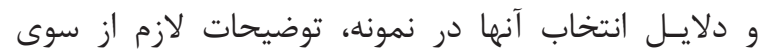

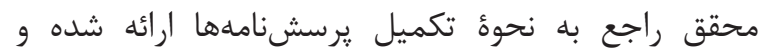

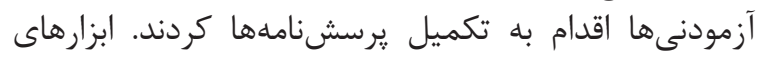

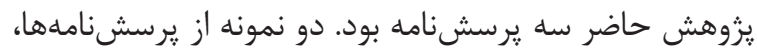

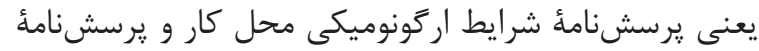

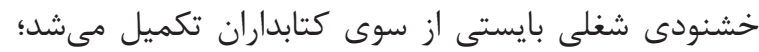

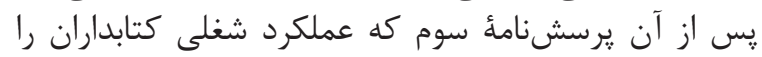

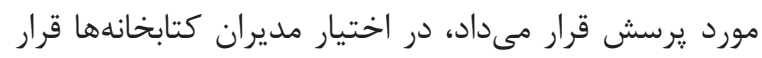

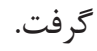

\section{تجزيهوتحليل آمارى}

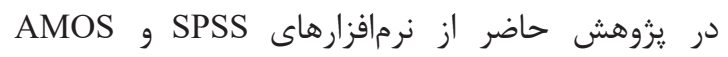
ويراست \1 استفاده شد. براى بينش اوليه، از آمار توصيفى
فرضيهها

فرضئ اول: شرايط اركونوميكى بر خشنودى شغلى اثر

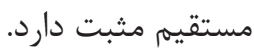
فرضيأ دوم: خشنودى شغلى بر عملكرد شغلى اثر مستقيم دارد.

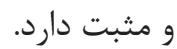

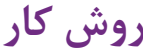

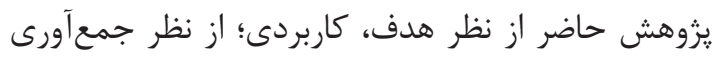

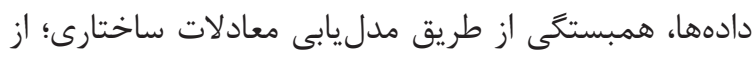

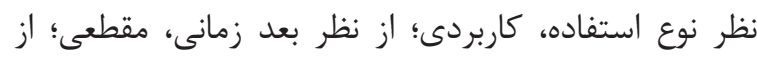

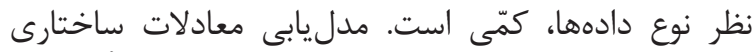

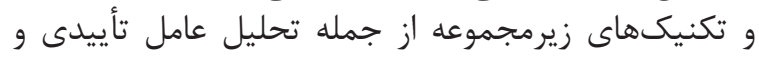

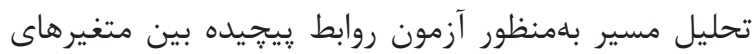

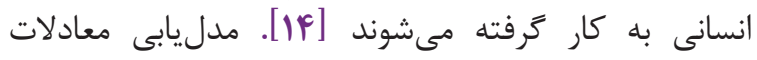

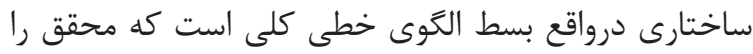

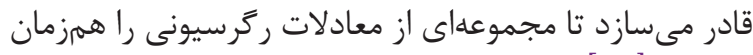

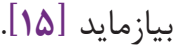

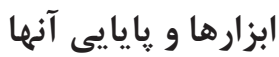

در اين مطالعه بامنظور اندازهكيرى متغيرها ابزارهاى زير اليها

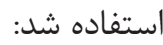

\section{سنجش خشنودى شغلى}

در يزوهش حاضر براى سنجش خشنو حسنى سنى شغلى از مقياس

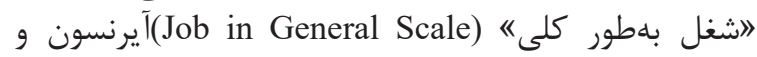

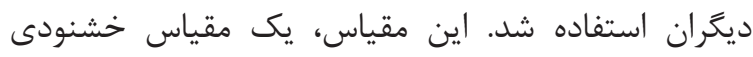

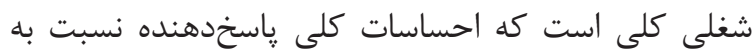

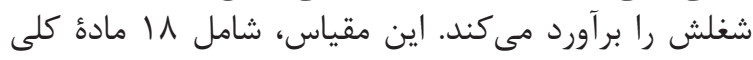

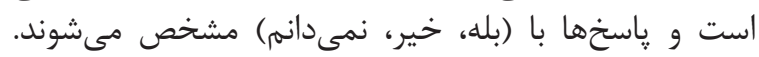

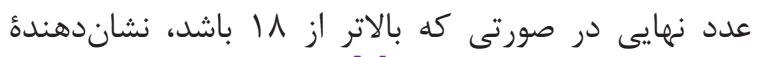

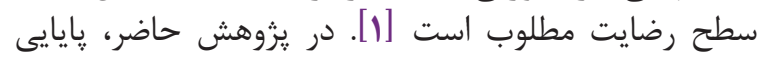

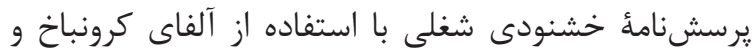

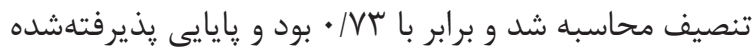

\section{بر بـى شرايط اركونوميك}

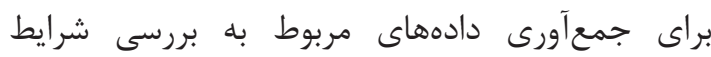

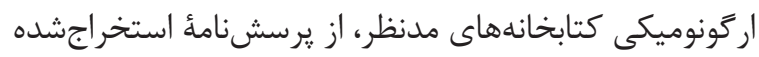

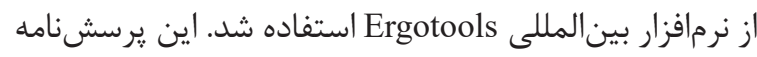

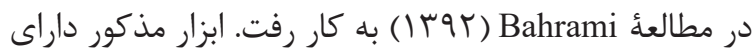

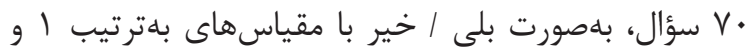

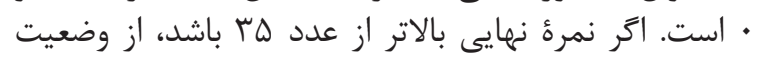




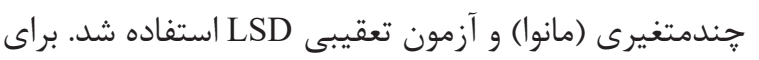

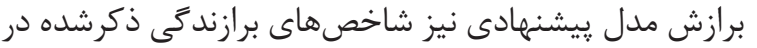
جدول ا بهكار كرفته شد.
مثل ميانكَين و انحرافمعيار استفاده شد. بهمنظور تحليل

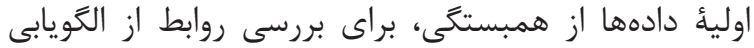

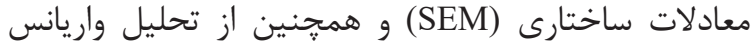

جدول ا.شاخص هاى برازش مدل پيشنههادى

\begin{tabular}{|c|c|c|c|c|}
\hline برازش مدل بيشنهادى & برازش قابل قبول & اختصار & نام شاخص & رديف \\
\hline TF/VT & $\cdot 1 \cdot \Delta<$ & $X^{2}$ & 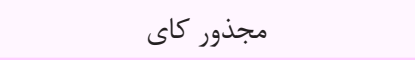 & 1 \\
\hline $1 / \cdot V$ & $\Delta>$ & $X^{2} / d f$ & مجذور كاى نرمال & r \\
\hline$\cdot / \cdot r$ & $\cdot \mid \cdot \Delta>$ & RMSEA & جذر ميانكَين مجذورات خطاى تقريب & r \\
\hline .1941 & $q / \cdot \leq$ & GFI & 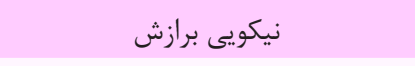 & r \\
\hline$\cdot / \wedge \wedge \Delta$ & $\Lambda \Delta / \cdot \leq$ & AGFI & نيكويى برازش تعديل شده & $\Delta$ \\
\hline .1999 & $.19<$ & CFI & برازندگى تطبيقى & 4 \\
\hline .1999 & نزديك به & IFI & برازندگى افزايشى & v \\
\hline$\cdot / 9 \Delta r$ & $9 / \cdot \leq$ & NFI & شاخص نرم شده برازندگى & $\wedge$ \\
\hline .1994 & $.19<$ & NNFI & شاخص نرم شدگى برازندگى & 9 \\
\hline
\end{tabular}

الكوى يِيشنهادى، نتايج در جدول ب ارائه شدند.

كافتهها

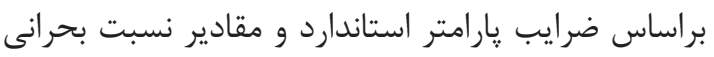

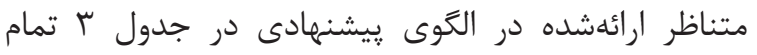
مسيرهاى مستقيم معنى دار هستند. در شكل r ضرايب استاندارد مسيرهاى الكوى بيشنهمادى مشاهده مىشود.

\section{اطلاعات جمعيتشناختى} بررسى اطلاعات جمعيتشناختى، در جدول r ارائه شدند. فرضيههاى مربوط به مسيرهاى مستقيم در الكوى

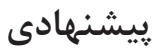
در بررسى فرضيههاى مربوط به مسيرهاى فرضشده در

جدول r. متغير هاى جمعيتشناختى

\begin{tabular}{|c|c|c|c|}
\hline درصد & فراوانى & & \\
\hline r & $r \cdot$ & مرد & \multirow{2}{*}{ جنسيت } \\
\hline$V G / T$ & $g f$ & 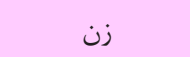 & \\
\hline$r M / F$ & 11 & آنا r & \multirow{4}{*}{$\begin{array}{c}\text { رَووه سنى } \\
\text { (سال) }\end{array}$} \\
\hline$\Delta \Lambda / \mu$ & pq & اr & \\
\hline $\mid f / r$ & it & $\Delta \cdot\left(F^{\mid}\right)$ & \\
\hline $9 /$. & $\Delta$ & G. & \\
\hline $\mid \Delta / F \lambda$ & Ir & دييلم و پايين تر & \multirow{4}{*}{ سطح تحصيلات } \\
\hline$\Delta / 9 \Delta$ & $\Delta$ & فوق دييلم & \\
\hline$r N / \cdot q$ & rt & ل ليسانس & \\
\hline$f \cdot / \uparrow \lambda$ & rF & فوق ليسانس & \\
\hline$r q / \Lambda$ & $r \Delta$ & مجرد & \multirow{2}{*}{ وضعيت تاهل } \\
\hline$V \cdot / r$ & $\Delta 9$ & متاهل & \\
\hline
\end{tabular}




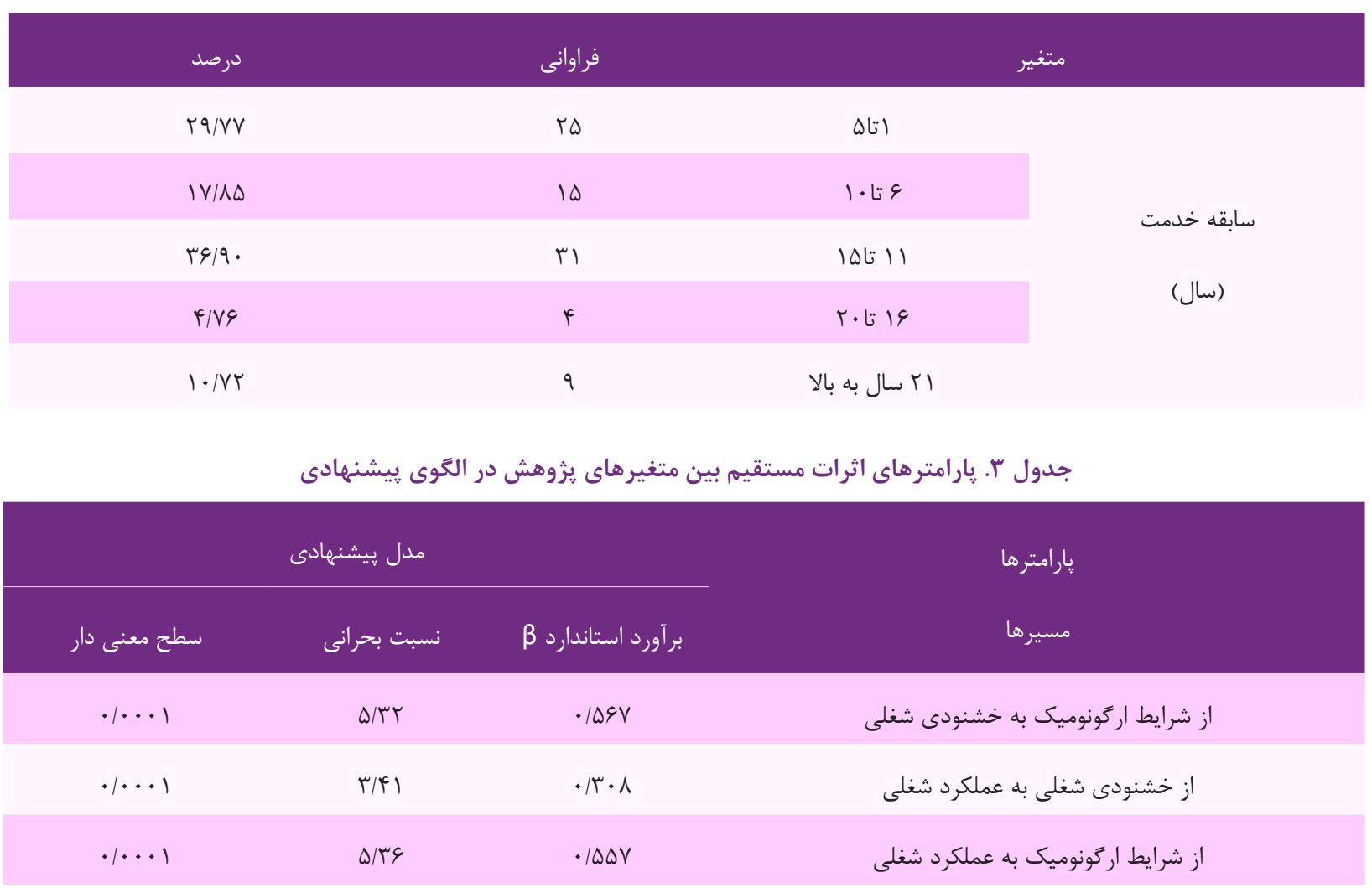

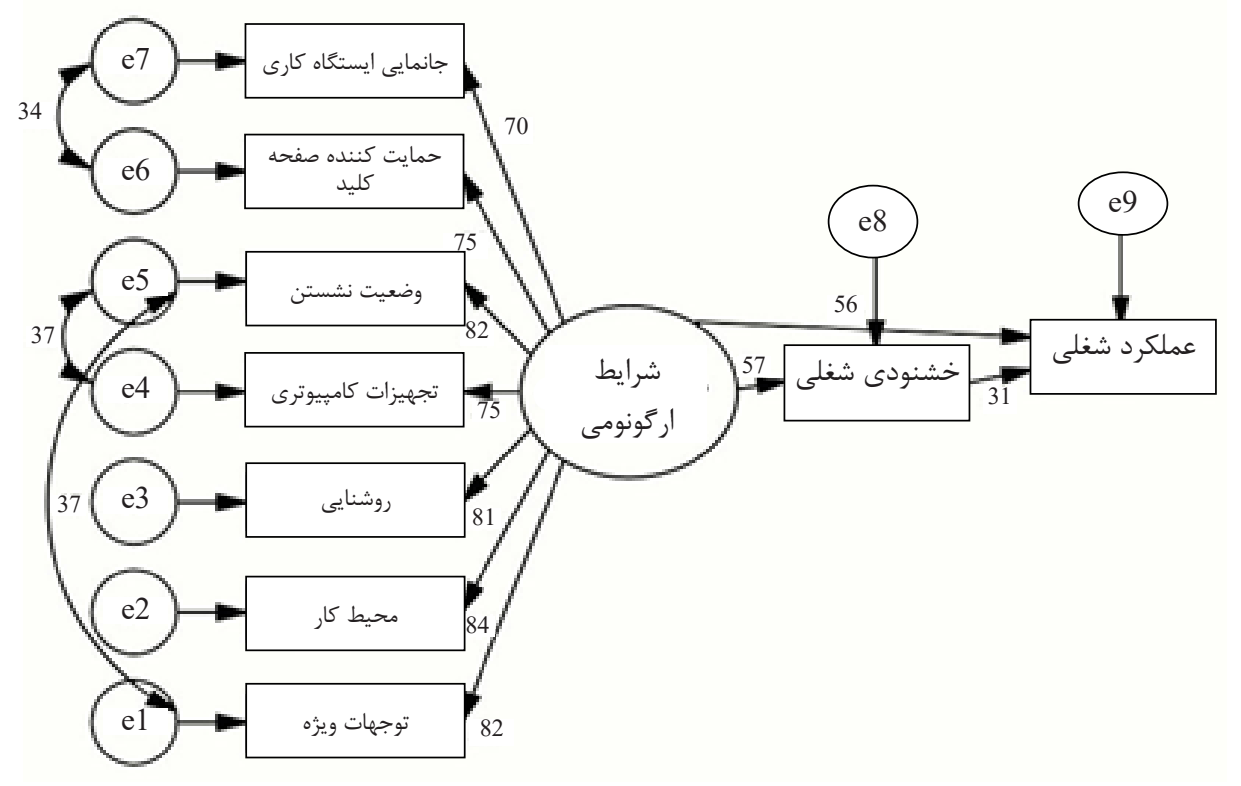

شكل r. ضرايب استاندارد مسيرهاى الكَوى بيشنهادى

جدول شمارهُ F. فرضيهها

فرضيه

ضريب مسير مستقيم شرايط ارگونوميك به

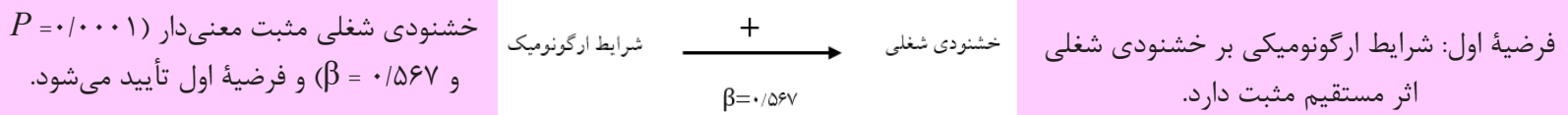




$$
\text { فرضيه دوم: خشنودى شغلى بر عملكرد شغلى اثر مستقم و مثبت دارد. }
$$

ضريب مسير مستقيم شرايط ارگَونوميك به

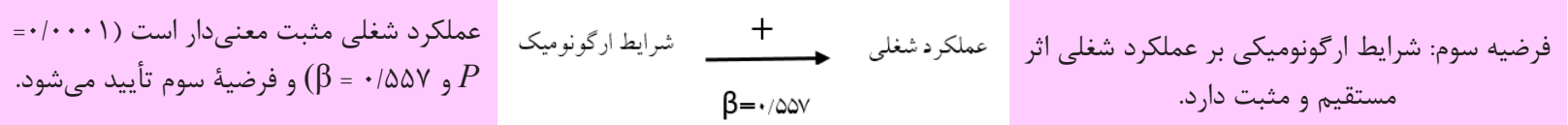

يريجر (Hayes \& Preacher) (IV] از طريق ماكروى اين

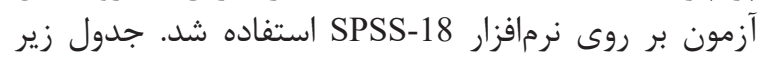
نشاندهنده ارزشهاى مربوط به اين مسيرها است

$$
\begin{aligned}
& \text { فرضئُ جهارم: شرايط ارگونوميكى (از طريق خشنودى } \\
& \text { شغلى) بر عملكرد شغلى اثر مثبت غيرمستقيم دارد. } \\
& \text { براى تعيين معنىدارى اثر غيرمستقيم، از آزمون هايز و }
\end{aligned}
$$

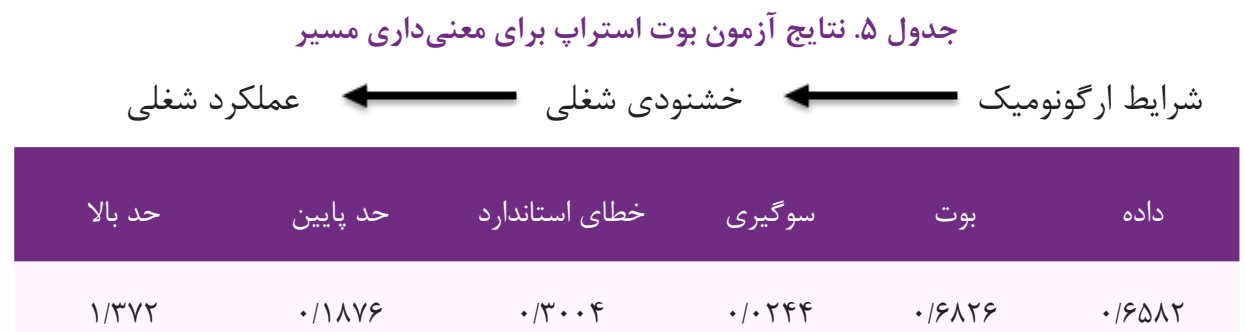

DaneshFard, Chahardoli مطالعهُ Shokrkon ] رابطهُ ضعيفى بين اين دو متغير نشان

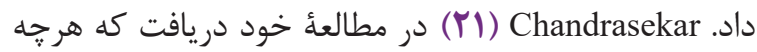
انغيزه شغلى بيشتر باشد، خشنودى شغلى نيز بالاتر است و

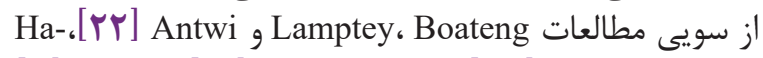

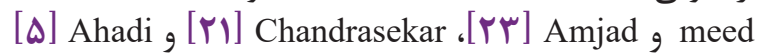
حاكى از ارتباط مستقيم و مثبت بين انخيزه شغلى و عملكرد

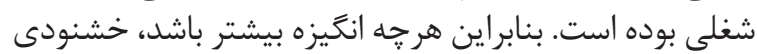

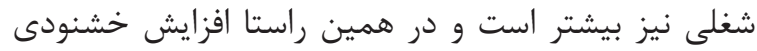
شغلى نيز باعث افزايش عملكرد شغلى ميثى آشود.

مسير مستقيم الكو از شرايط ارگونوميك به عملكرد

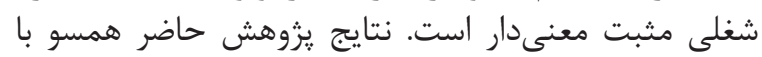

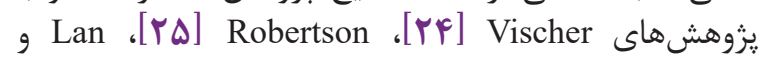

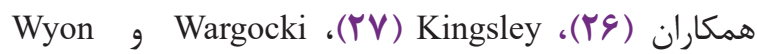
Am- Hameed ، [rq] Seppänen, Fisk, \& Lei ، [r^] Yuan ، [r*] Kahya ، [r)] Chandrasekar ، [ru] jad Ra- , Babaee ،[r/] Hancock , Szalma [r)] Zain- مimZadeh

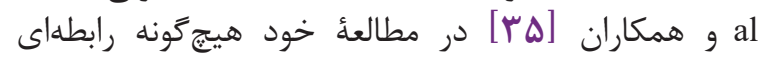

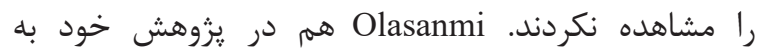

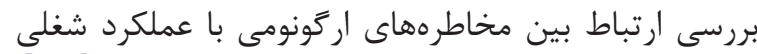

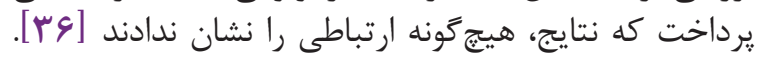
Karakolis \& Callaghan

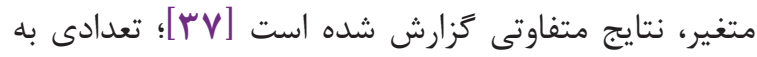

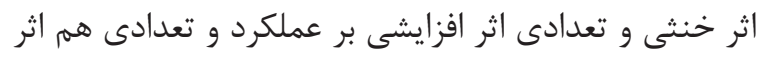

همانطور كه در جدول ه مشاهده مىشود، حد پإيين

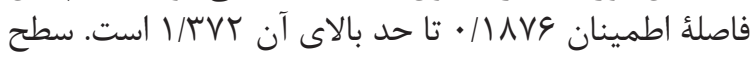

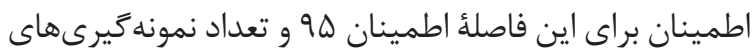

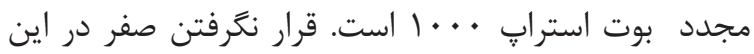

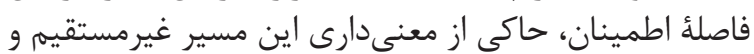
تأييد اين فرضيه است.

\section{بحث ونتيجه تيرى}

يافتههاى يزوهش نشان داد كه براساس تحليلهاى

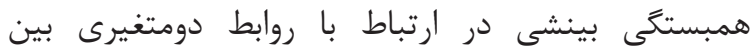

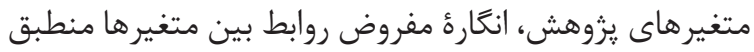

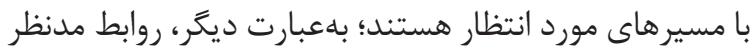

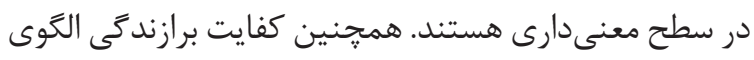

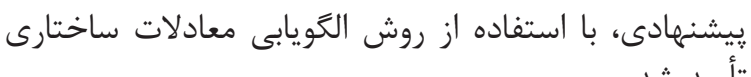
تأييد شد.

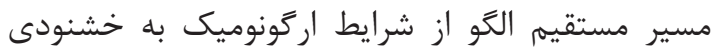

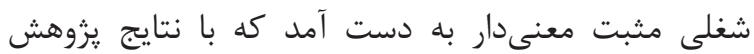

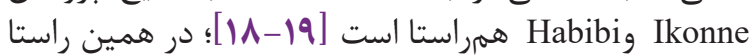
افزايش خشنودى شغلى باعث افزايش عملكرد شغلى مى شى استود.

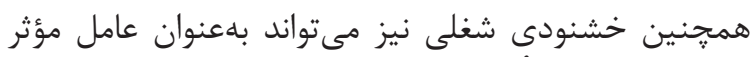

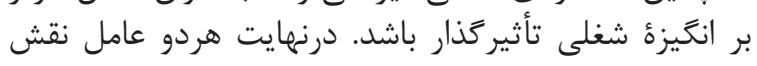

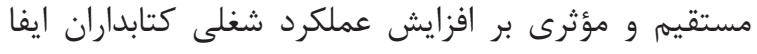
خواهند كرد. مسير مستقيم الكو از خشنودى شغلى به عملكرد شغلى Arshadi، مثبت معنى دار است. نتايج يثوهش حاضر با نتايج 


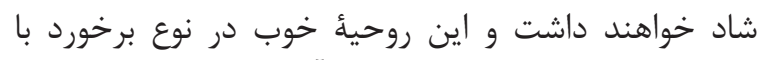

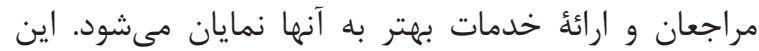

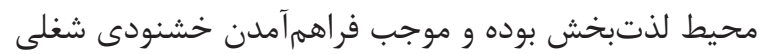

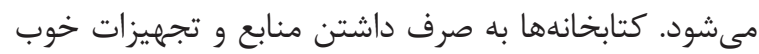

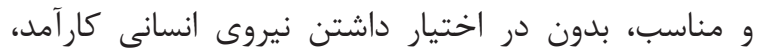

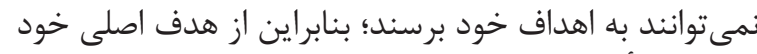

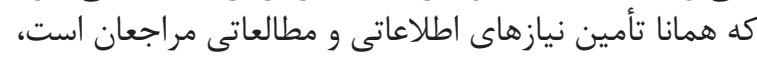

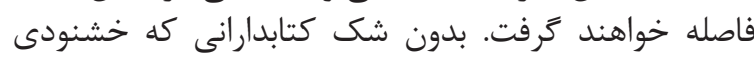
شغلى آنها در سطح بالايى باشد، عملكرد خوبى نيز دارند. عملكرد شغلى بلهنوان ارزش كلى مورد انتظار سازمانها

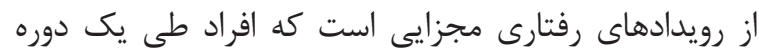

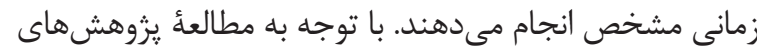

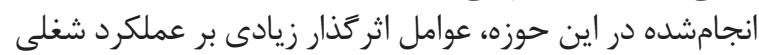

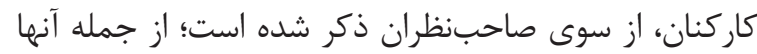

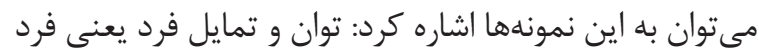

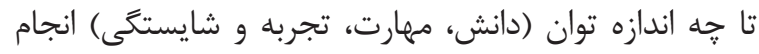

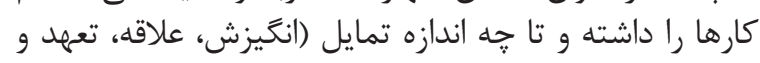

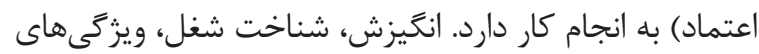

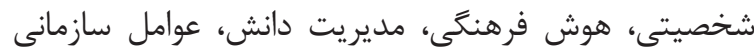

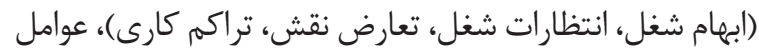

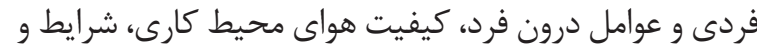

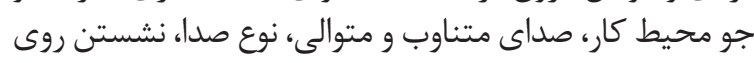

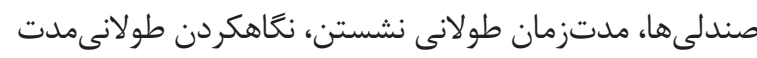

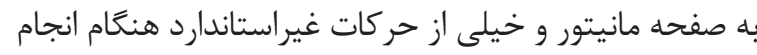

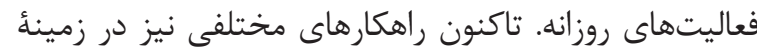

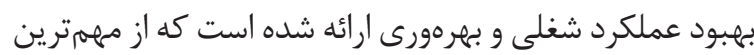

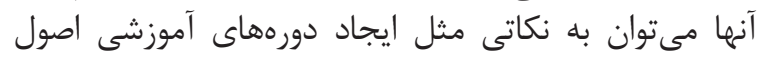

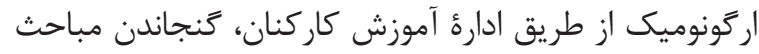

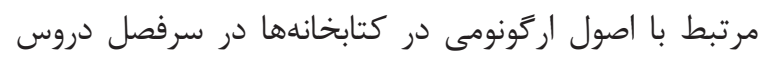

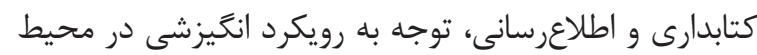
كار، آكاهساختن كار كنان از اثربخشى ترجئ آنان در عملكرد و و ... اشاره

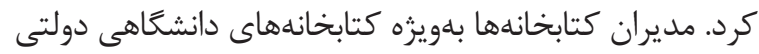

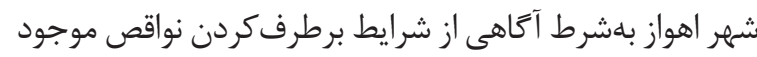

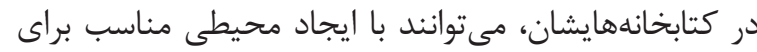

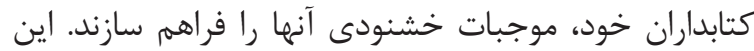

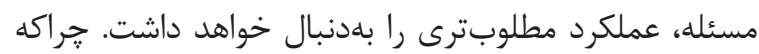

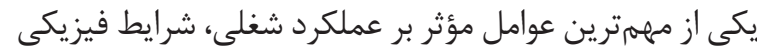

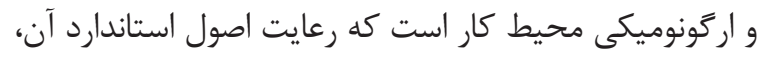

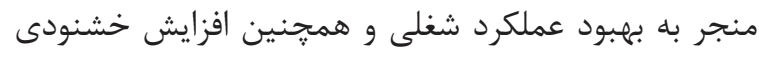

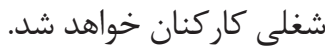

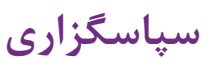

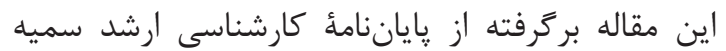

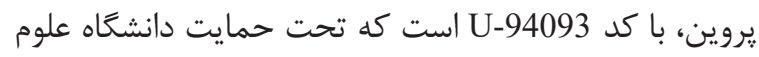
يزشكى جندى بايور اهواز انجام شد.

\section{تعارض منافع}

بين هيج كدام از نويسندكان تعارضى در منافع مربوط به

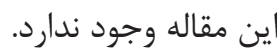

كاهشى بر عملكرد داشتند.

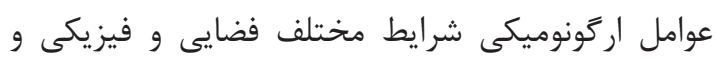

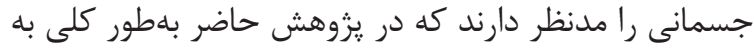

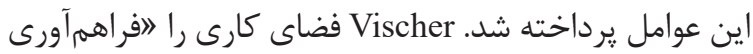

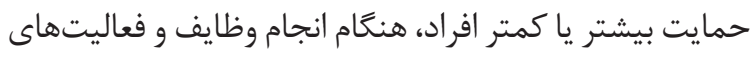

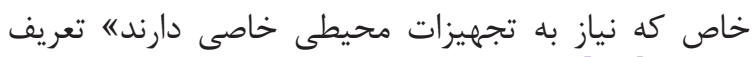

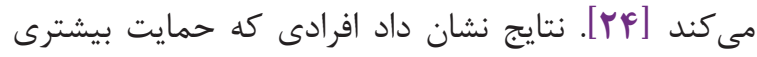

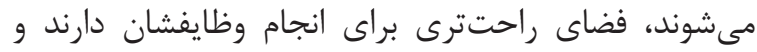

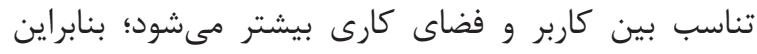

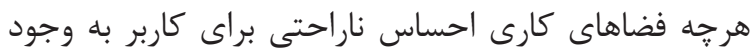

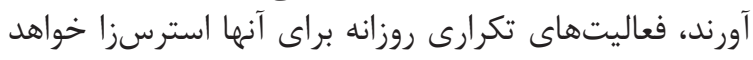

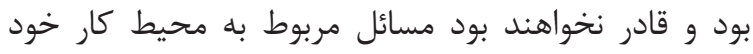

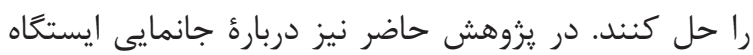

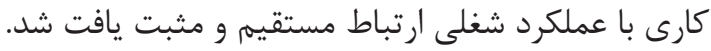

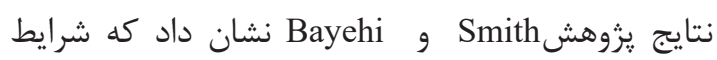

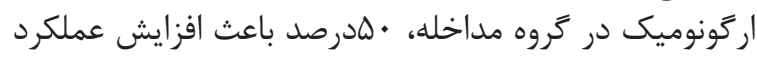

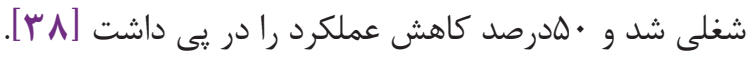

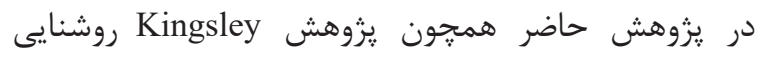

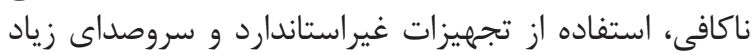

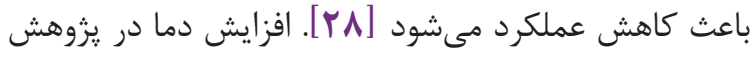

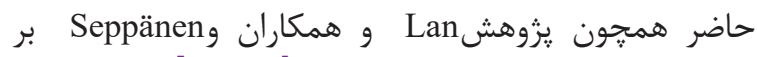

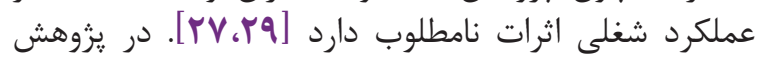

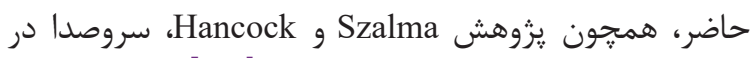

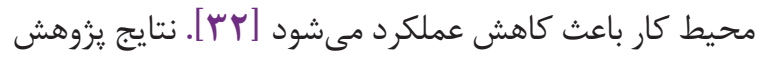

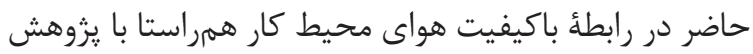

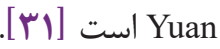

در يروهش حاضر، مسير مستقيم الكَ از شرايط اركونوميك

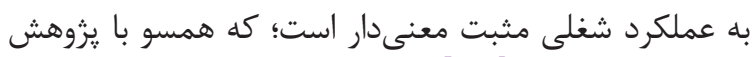
MaktabDar

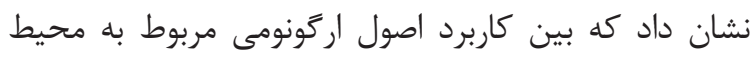

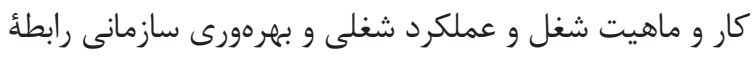

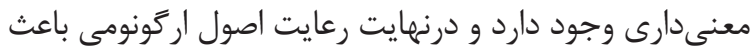

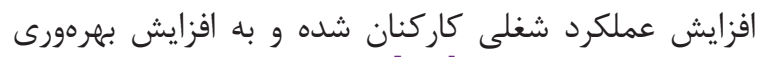

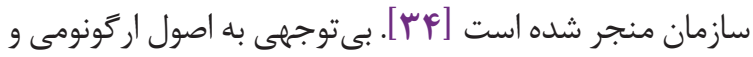

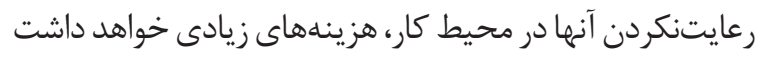

و موجب كاهش كارايى و افزايش استرس كار كنان ينان مى خوشود.

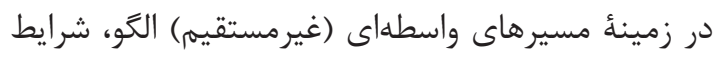

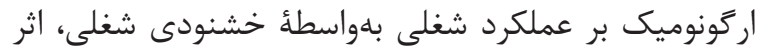

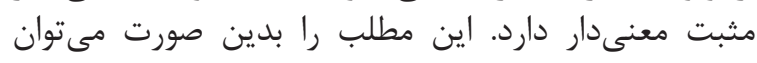

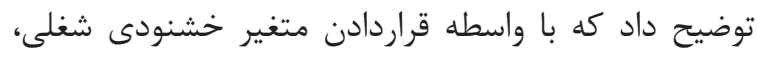

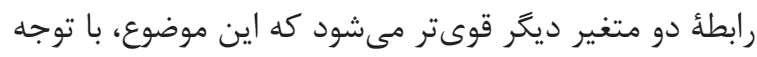

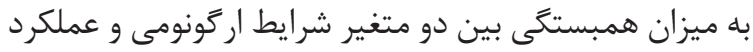

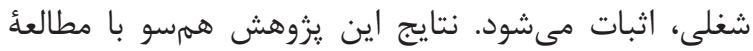

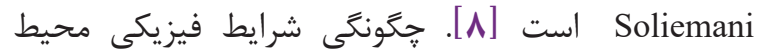

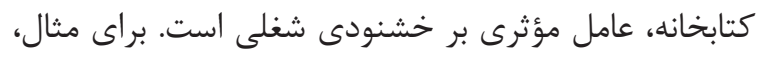

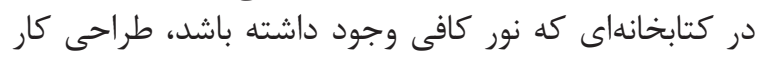

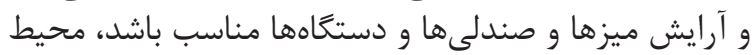
آرام باشد، كتابداران و كاركنان كتابخانه همواره روحيداى دائ دانيط 


\section{Reference}

1. Ironson GH, Smith PC, Brannick MT, Gibson WM, Paul KB. Construction of a Job in General scale: A comparison of global, composite, and specific measures. Journal of applied psychology. 1989 Apr;74(2):193. https://doi. org/10.1037/0021-9010.74.2.193

2. Farajpahlou A, Nooshinfard F, Hassanzadeh M. Performance Appraisal of Librarians by 360 Degree Feedback: the Case of Public librarians of Guilan Province, Iran. Research on Information Science \& Public Libraries. 2013; 18(4): 421442.

3. Maier NRF. Psychology in Industry. Boston: The Riverside Press; 1955. 46-51.

4. Ghazinoori S. Human resources engineering. Tehran: Payam-e-Noor; 1381. 21-29.

5. Ahadi B, Fathi A, AbdolMohamadi K. Study of psychological factors affecting on job performance of East Azarbaijan NAJA staff. East Azarbaijan Military Knowledge. 2014;4(15):6378.

6. Azimi H, Gudarzi G, Ansari M, Pirayesh R, Abdizarin S. Designing a Questionnaire for the Assessment of Job and Organizational Attitudes of Government Employees, Case Study: 80 Government Organizations in Zanjan Province. Strategic Management Thought. 2011; 1(5): 169-200.

7. Shokrkon H, Na'ami A heelationship. The relationship of job satisfication with organizational citizenship behavior and job performance in ahvaz factory workers. Journal of Education and Psychology. 2008; 3(2)39-52.

8. Soliemani M. Librarians' job satisfaction and its impact on the quality of library services. Journal of academic Librarianship and information research. 2000; 35(32): 49-60.

9. Definition and Domains of Ergonomics [Internet]. International Ergonomics Association. 2016 [cited 2017 Jul 24]. Available from: http://www. iea.cc/whats/

10. Introduction to human factors [Internet]. HSE. [cited 2019 feb 16]. Available from:[http://www. hse.gov.uk/humanfactors/introduction.htm]

11. Morel G, Amalberti R, Chauvin C. How good micro/macro ergonomics may improve resilience, but not necessarily safety. Safety science. 2009 Feb 1;47(2):285-94. https://doi.org/10.1016/j. $\underline{\text { ssci.2008.03.002 }}$

12. Habibi E, Amini N, Porabdian S, Rismanchian M. Assessment of relationship between Macro Ergonomic conditions and employees work satisfaction Touse-eh and Omran factory. Iran Occupational Health. 2008 Apr 15;5(1):15-20.

13. Carayon P. Macroergonomics in quality of care and patient safety. Human factors in organizational design and management-VII. 2003:2134.

14. Alavi M. Reporting the results of structural equation modeling (SEM) writing. Quarterly Journal of Nursing Management. 2014 Sep 15;3(2):8-19.

15. Arshadi N, Shokrkon H, Yailagh MS. Designing and testing a model of important precedents and outcomes of work motivation of national Iranian south oil company employees in Ahvaz region, Iran. International Journal of Psychology. 2008 Jun 1;43(3):232.

16. Bahrami L. Survey ergonomic conditions in public libraries of Khuzestan province and physical damages caused by the lack of ergonomic principals among librarians. MS theise of Ahvaz University of Shahid Chamran; 2013.

17. Hayes AF, Preacher KJ. Statistical mediation analysis with a multicategorical independent variable. British Journal of Mathematical and Statistical Psychology. 2014 Nov;67(3):451-70. https://doi.org/10.1111/bmsp.12028

18. Ikonne $\mathrm{CN}$. Influence of workstation and work posture ergonomics on job satisfaction of librarians in the federal and state university libraries in Southern Nigeria. IOSR Journal Of Humanities And Social Science. 2014;19(9):78-84. https:// doi.org/10.9790/0837-19947884

19. Chahardoli S, Motamedzade M, Hamidi Y, Golmohammadi R, Soltanian AR. Relationship between job design, performance and job satisfaction among Bank employees. Health and Safety at Work. 2014 Sep 15;4(3):75-84.

20. DaneshFard K, Mahjoob S. Examine the relationship between job satisfaction and organizational commitment to employee performance. Quarterly Leadership and Education Management. 2009; 4(3): 115-136. 
21. Chandrasekar K. Workplace environment and its impact on organisational performance in public sector organisations. International journal of enterprise computing and business systems. 2011 Jan;1(1):1-9.

22. Lamptey R, Boateng M, Antwi I. Motivation and Performance of Librarians in Public Universities in Ghana. Libr Philos Pract [Internet]. 2013;1-25.

23. Hameed A, Amjad S. Impact of office design on employees productivity: a case study of banking organizations of Abbottabad, Pakistan. 2009;3(1):1-13.

24. Vischer JC. The effects of the physical environment on job performance: towards a theoretical model of workspace stress. Stress and Health: Journal of the International Society for the Investigation of Stress. 2007 Aug;23(3):175-84. https://doi.org/10.1002/smi.1134

25. Robertson M, Amick III BC, DeRango K, Rooney T, Bazzani L, Harrist R, Moore A. The effects of an office ergonomics training and chair intervention on worker knowledge, behavior and musculoskeletal risk. Applied ergonomics. 2009 Jan 1;40(1):124-35. https://doi.org/10.1016/j. apergo.2007.12.009

26. Lan L, Wargocki P, Lian Z. Thermal effects on human performance in office environment measured by integrating task speed and accuracy. Applied ergonomics. 2014 May 1;45(3):490-5. https://doi.org/10.1016/j.apergo.2013.06.010

27. Asante K. The impact of office ergonomics on employee performance; a case study of the Ghana National Petroleum Corporation (GNPC) (Doctoral dissertation).

28. Wargocki P, Wyon DP. The effects of moderately raised classroom temperatures and classroom ventilation rate on the performance of schoolwork by children (RP-1257). Hvac\&R Research. 2007 Mar 1;13(2):193-220.

29. Seppänen O, Fisk W, Lei Q. Effect of Temperature on Task Performance in Office Environment. 5th International Conference on Cold Climate Heating, Ventilating and Air Conditioning. Moscow, Russia; 2006. p. 11.

30. Kahya E. The effects of job characteristics and working conditions on job performance. International journal of industrial ergonomics. 2007
Jun 1;37(6):515-23. https://doi.org/10.1016/j.ergon.2007.02.006

31. Yuan L. Reducing ergonomic injuries for librarians using a participatory approach. International Journal of Industrial Ergonomics. 2015 May 1;47:93-103. https://doi.org/10.1016/j.ergon.2015.03.004

32. Szalma JL, Hancock PA. Noise effects on human performance: a meta-analytic synthesis. Psychological bulletin. $2011 \mathrm{Jul} ; 137(4): 682$. https://doi. org/10.1037/a0023987

33. Babaee S, RahimZadeh A. Factors affecting the workplace ergonomics. In Second International Symposium on Management Sciences with a focus on sustainable development. Kerman: Kerman Azad Islamic University. 2015.

34. Maktabdarb H. Regarding the application of ergonomic principles with job performance and productivity Staff Charity Committee Fars province. MA theisis of Marvdasht Azad Islamic University. 2011.

35. Zainal M, Zahid B, Yang HA, Azhar BNZ, Maimon BH. The Relationships Between Stress Level, Ergonomics, Interpersonal Skills And Job Performance: A Case Study At Wisma Negeri, Negeri Sembilan, Malaysia.

36. Olasanmi OO. Effect of ergonomic hazards on job performance of auditors in Nigeria. American Journal of Industrial and Business Management. 2016 Jan 21;6(01):33. https://doi.org/10.4236/ ajibm.2016.61003

37. Karakolis T, Callaghan JP. The impact of sitstand office workstations on worker discomfort and productivity: a review. Applied ergonomics. 2014 May 1;45(3):799-806. https://doi. org/10.1016/j.apergo.2013.10.001

38. Smith MJ, Bayeh AD. Do ergonomics improvements increase computer workers' productivity? an intervention study in a call centre. Ergonomics. 2003 Jan 1;46(1-3):3-18.

39. Rajabi G. Relationship between Job Characteristics and Job Satisfaction in Shiraz Refinery Employees. Quarterly Journal of Career \& Organizational Counseling. 2013; 14(5): 106-118.

40. Asaolu AO, Itsekor V. Ergonomic computer workstation considerations for library staff. International Journal of Academic Library and In- 
formation Science. 2014;3(2):22-6.

41. DeConinck JB, Stilwell CD. Incorporating organizational justice, role states, pay satisfaction and supervisor satisfaction in a model of turnover intentions. Journal of Business Research. 2004 Mar 1;57(3):225-31.https://doi.org/10.1016/S01482963(02)00289-8

42. DiyanatNasab M, Javidi H, Baghuli H. The Medition role of Job stress in the Relationship Between Psychological Capital and Personnels Performance of Gachsaran Oil and Gas Company Operating in Dashtgaz. Psychological methods and models. 2014; 15(4): 75-90.

43. Gavgani VZ, Nazari J, Jafarabadi MA, Rastegari F. Is librarians' health affected by ergonomic factors at the work place? Library Philosophy \& Practice. 2013; 1-16.

44. Ghazanfari A, Abedi L. Survey satisfaction, motivation and job performance of a military school's staff. Research in Human Resource Management. 2008; 1(1): 149-175.

45. Letvak S, Buck R. Factors influencing work productivity and intent to stay in nursing. Nursing Economics. 2008 May 1;26(3):159-67.
46. Mehrabian F, Nasirpour AA, Keshavars Mohamadian S. Factors affecting human resources productivity in guilan University of medical sciences using path analysis. ZUMS Journal. 2011 Apr 1;19(75):94-106.

47. MirHosieni Z, GholiZadeh N. Investigating the physical injuries of workplace among librarians of governmental universities of Isfahan based on Ergonomic principles. Epistemology. 2007; 11(3): 117-133.

48. Osareh F, Bigdeli Z, Morovati Z, Hoseini M. A Survey of Relationship between Cultural Intelligence and Librarians' Job Performance in the Public Libraries of Khuzestan. Research on Information Science \& Public Libraries. 2013; 1(22): 141-157.

49. Van Saane N, Sluiter JK, Verbeek JH, Frings-Dresen $\mathrm{MH}$. Reliability and validity of instruments measuring job satisfaction - a systematic review. Occupational medicine. 2003 May 1;53(3):191200. https://doi.org/10.1093/occmed/kqg038 